\title{
HUMAN RESOURCES AS A DETERMINANT OF ENSURING THE COMPETITIVENESS OF THE NATIONAL ECONOMY IN THE WORLD MARKET
}

\author{
Elena S. Shilets \\ Donetsk National University, Donetsk, Donetsk People s Republic
}

\begin{abstract}
In modern conditions of world economic relations, the key factor ensuring the competitiveness of the national economy in the world arena is labor resources. The potential and sustainable growth of enterprises directly depend on the development of the human capital, the level of its education, qualifications and mobility. The article examines the levels and spheres of human resources manifestation, and the directions that form the necessary degree of development of the companys competitive advantages. It has been determined that international competitiveness directly depends on the effectiveness of the business strategy, first of all, at the level of the enterprise itself, the management of which must form the staff based on its strategic goals so that the alignment of human talent and the market takes place in time. A conceptual scheme for ensuring the international competitiveness of the national economy based on the development of human resources has been developed, which includes a group of factors that must be taken into account in strategic and tactical planning. At the same time, effective planning of the personnel potential should be based on the key capabilities of the organization in accordance with the business strategy, motivation and development of personnel, its possible operational relocation, as well as ensuring the sustainability of the organization in terms of personnel.
\end{abstract}

Key words: human resources, competitiveness, competitive advantages, personnel, effective management.

Citation. Shilets E.S. Human Resources as a Determinant of Ensuring the Competitiveness of the National Economy in the World Market. Journal of Volgograd State University. Economics, 2020, vol. 22, no. 3, pp. 98-108. (in Russian). DOI: https://doi.org/10.15688/ek.jvolsu.2020.3.9

\section{ЧЕЛОВЕЧЕСКИЕ РЕСУ РСЫ КАК ДЕТЕРМИНАНТ ОБЕСПЕЧЕНИЯ КОНКУРЕНТОСПОСОБНОСТИ НАЦИОНАЛЬНОЙ ЭКОНОМИКИ НА МИРОВОМ РЫНКЕ}

\author{
Елена Станиславовна Шилец \\ Донецкий национальный университет, г. Донецк, Донецкая Народная Республика
}

\begin{abstract}
Аннотация. В современных условиях мирохозяйственных связей ключевым фактором, обеспечивающим конкурентоспособность национальной экономики на мировой арене являются трудовые ресурсы. Потенциал и устойчивый рост предприятий напрямую зависят от развития человеческого капитала, уровня его образования, квалификации и мобильности. В статье исследованы уровни и сферы проявления человеческих ресурсов и направления, формирующие необходимую степень развитости конкурентных преимуществ компании. Определено, что международная конкурентоспособность напрямую зависит от эффективности бизнес-стратегии, прежде всего на уровне самого предприятия, руководство которого должно сформировать штат исходя из своих стратегических целей так, чтобы происходило выравнивание человеческого таланта и рынка во времени. Разработана концептуальная схема обеспечения международной конкурентоспособности национальной экономики на основе развития человеческих ресурсов, включающая в себя группы факторов, которые необходимо учитывать при стратегическом и тактическом планировании. При этом эффективное планирование кадрового потенциала
\end{abstract}


должно основываться на ключевых способностях организации согласно бизнес-стратегии, мотивации и развития персонала, возможном оперативном его перемещении, а также обеспечении устойчивости организации в части персонала.

Ключевые слова: человеческие ресурсы, конкурентоспособность, конкурентные преимущества, персонал, эффективное управление.

Цитирование. Шилец Е. С. Человеческие ресурсы как детерминант обеспечения конкурентоспособности национальной экономики на мировом рынке // Вестник Волгоградского государственного университета. Экономика. - 2020. - Т. 22, № 3. - C. 98-108. - DOI: https://doi.org/10.15688/ek.jvolsu.2020.3.9

\section{Введение}

В условиях рыночной экономики ключевым фактором успеха государства на мировом рынке является его конкурентоспособность, которая определяется важнейшими конкурентными преимуществами, составляющими основу развития в современных условиях усиления интернационализации хозяйственной деятельности и кардинально нового вектора развития международных экономических отношений.

Классические понятия конкурентоспособности определяются авторами, как правило, как проявление способности конкурировать, «соревноваться» в своих характеристиках товаров, услуг, человеческих ресурсов, их квалификации, территориальной и институциональной базы, уровня развития и взаимодействия сферы научно-исследовательских организаций и предприятий, составляющих основу развития национальной экономики, функционирование кластеров, зон свободной торговли, регулирования экономики и др. [Айдинова и др., 2015, с. 372]. Эти показатели отражают уровень востребованности производителей, товаров, услуг на разного рода рынках - глобальном, национальном, региональном, а также степень соответствия характеристик объекта рыночным требованиям по сравнению с другими аналогами.

\section{Материал и методы исследования}

Теоретическую и методическую основу исследования составили труды ведущих зарубежных и российских ученых в области конкурентоспособности национальной экономки и человеческих ресурсов. В работе использованы общенаучные методы исследования, а также инструменты статистико-экономического анализа.

\section{Результаты исследования и их обсуждение}

На современном этапе рыночных отношений одним из основных конкурентных преимуществ и национальным богатством каждого государства являются человеческие ресурсы или человеческий капитал, определяющий функционирование приведенных выше показателей и непосредственно формирующий направления развития, приоритетность отраслей и структуру экономики, внешнюю политику и внутренний баланс интересов общества и бизнеса, составляющий основу конкурентоспособности национальной экономики [Баканова, 2014, с. 13; Воронина, 2016, с. 75].

Конкурентоспособность человеческих ресурсов представляет собой набор качеств, который определяет преимущества их носителя в системе трудовых отношений в сравнении с другими их участниками. Качества, которые данный набор образуют и по разным критериям оказываются лучше, чем у других их носителей (конкурентов), представляют собой конкурентные преимущества.

В контексте исследования конкурентоспособности человеческого капитала следует различать сферы его проявления: индивидуальный (уровень личности) зависит от личных обстоятельств жизни человека, личностных характеристик, квалификации, жизненной активности; коллективный (уровень организации) зависит от организаций, в которых учился и работал человек, сфер их деятельности, необходимость взаимодействия с наукой и бизнесом; общественный (уровень общества или сообщества, к которому принадлежат человеческие ресурсы) [Базык, 2015, с. 5].

Также необходимо отметить уровни его развития, которые отражают степень агрегирования человеческих ресурсов - уровень индивида, предприятия (микро), региона / от- 
расли (мезоуровень), национальной экономики (макроуровень) и мирового хозяйства (международный) [Богатырева, 2014].

На каждом приведенном уровне существуют группы факторов, которые формируют степень развитости приведенных конкурентных преимуществ. Так, на макроуровне:

1) ко внутренним факторам относятся как количественные характеристики трудовых ресурсов (численность населения, доля трудоспособного, естественный прирост, рождаемость, уровень миграции и т. д.), так и качественные (производительность труда, состав занятых по уровню образования, доля работников, занятых в сфере научно-исследовательских и опытно-конструкторских разработок);

2) ко внешним - уровень развития институциональной сферы: законодательной базы, нормативно-правовой системы, налогового, трудового, миграционного законодательства; социально-экономические - доход, затраты на образование, уровень образовательной системы, прожиточный уровень, структура социальных гарантий и защиты; рынок труда уровень безработицы, емкость рынка по областям экономики, развитость инфраструктуры, средний уровень заработной платы; предпринимательская среда - распределение предприятий по видам экономической деятельности, отраслевая структура, инновационная активность, развитость кредитной системы, поддержка государства малого и среднего предпринимательства, ограничение экспорта / импорта, иностранные инвестиции, открытость экономики и т. д.

На макро- и международном уровнях конкурентоспособность человеческих ресурсов общества зависит не только от совокупного интеллектуального капитала, но и от социальных, демографических, институциональных, экономических и культурных факторов. Международная конкурентоспособность человеческих ресурсов на макроуровне состоит из ряда направлений [Балтабек, 2016, с. 7].

Факторы международной конкурентоспособности человеческих ресурсов по характеру действия, как уже было отмечено, можно разделить на внутренние и внешние. Внутренние определяют конкурентоспособность субстанционно, задавая набор конкурентных преимуществ. Внешние влияют косвенно, через сферу их формирования и реализации. Любой из внешних факторов детерминирует изменения в наборе внутренних факторов. Данный факт должен учитываться при выработке стратегии государственного регулирования, что предполагает:

- институциональное обеспечение равных стартовых возможностей в конкуренции и ориентацию государственной антимонопольной политики на единую конкурентную среду;

- укрепление институциональных позиций работника в трудовых отношениях и госконтроль методов реализации интересов со стороны как работника, так и работодателя;

- оптимизацию соотношения экономических источников воспроизводства человеческих ресурсов - факторных доходов и социальных трансфертов как факторов стимулирующего и дестимулирующего характера;

- поощрение вложений в человеческий капитал, в том числе увеличение государственных инвестиций в образование и профессиональную подготовку [Биганова и др., 2017, c. 23].

С целью повышения международной конкурентоспособности человеческих ресурсов система трудовых отношений должна базироваться на: преимущественно переговорном характере устранения разногласий; согласовании социально-экономической политики, особенно в сфере политики доходов; утверждении общечеловеческих ценностей в производстве и других сферах использования человеческих ресурсов. При этом международная конкурентоспособность непосредственно зависима от конкурентоспособности на национальном, отраслевом, а в большей степени на уровне предприятий, организаций / компаний, которые формируют базис устойчивого развития национальной экономики [Дейнека и др., 2015, с. 228; Алавердов, 2015, с. 634; Аранжин, 2017].

При всем разнообразии концепций, описывающих работу с персоналом на предприятиях, ни одна из них не связывает сферу управления человеческими ресурсами и бизнес. На сегодняшний день целесообразно использовать именно такой подход, который является основой взаимопонимания и стратегического сотрудничества менеджмента и специалистов по персоналу. Здесь прослеживается 
связь между работой с кадрами, бизнес-стратегией и деловой средой, которая направлена на удовлетворение спроса, а значит, повышение конкурентоспособности товаров, работ, услуг. Кроме того, можно выделить специфические процессы человеческих ресурсов, непосредственно влияющие на реализацию стратегии [Moskowitz, 1975, p. 35; Potter et al., 1999, p. 262].

Любая компания, которая занимается бизнесом, существует в определенной деловой среде. Последняя включает потребителей, клиентов, пункты торговли, конкурентов, государственное регулирование и многочисленные условия, в которых функционирует бизнес на любом из уровней его функционирования.

Так, каждая организация должна сформулировать бизнес-стратегию, приоритеты и цели, призванные обеспечить ей успех в данных условиях. Важным критерием эффективности стратегии является также способность организации убедить клиента покупать товары и услуги у нее, а не у конкурентов. Работа любого сотрудника организации должна быть так или иначе направлена на достижение этой цели [Егоршин, 2015, с. 67; Кови, 2015, с. 168].

Для успеха компании необходима совокупность ключевых способностей, позволяющих реализовать разработанную стратегию. Под способностями в данном случае имеются в виду не квалификация и знания отдельных лиц, а базовый потенциал организации как единого целого.

Потенциал компании состоит из человеческих, технологических и финансовых ресурсов. Следовательно, существует непосредственная связь между конкурентными преимуществами на рынке и одаренностью персонала. Главная задача руководства - эффективное управление людьми с целью развития корпоративного потенциала и завоевания рынка. $\mathrm{Bce}$, что делают специалисты по человеческим ресурсам, должно концентрироваться на возможности активизации персонала, повышающего способность организации успешно реализовывать ее рыночную стратегию. В этом и заключается «вертикальное выравнивание» человеческого таланта и рынка. Из данной схемы вытекает следующий вывод: необходимо такое руководство кадрами, которое способно направить любую работу с персоналом (отдела человеческих ресурсов и менеджмента) на мобилизацию человеческого потенциала для завоевания рынков [Веснин, 2003, с. 328].

В концептуальной схеме выделены базовые процессы работы с человеческими ресурсами, определяющие факторы повышения конкурентоспособности национальной экономики (см. рисунок):

1. Планирование и комплектование штата. При наличии деловой стратегии удовлетворения текущей потребности в нужном персонале прогнозирование (планирование будущих потребностей) имеет первостепенное значение. Данная процедура предусматривает разработку методик привлечения, интеграции и сохранения необходимых талантов.

2. Обучение и развитие. Обеспечение компании нужными специалистами - важная задача. Ее потребности постоянно меняются. По некоторым оценкам, большинству сотрудников хватает приобретенной квалификации максимум на пять лет. В связи с этим для повышения общего уровня необходим налаженный процесс обучения и переподготовки.

3. Организационное развитие. Суть этого элемента - надзор за всеми организационными процессами и системами на предмет их соответствия бизнес-стратегии. Планирование, нормативы, трудовые процессы, финансовые сметы - все это можно усовершенствовать с целью раскрытия потенциала сотрудников.

4. Управления эффективностью. Кроме нужного персонала и налаженных организационных процессов необходим адекватный контроль за показателями деятельности; он должен подтвердить, что организация достигает желаемых результатов.

5. Отношения с работниками. Основу этого процесса составляет забота об индивидуальных потребностях сотрудников: чувствуя поддержку, они смогут работать энергичнее и эффективнее. Также данный процесс регулирует отношения между сотрудниками и всей организацией.

Перечисленные процессы составляют функции отдела человеческих ресурсов, а базовые элементы - работу с персоналом. Если в организации нет соответствующего отдела, она все равно должна применять эти принципы. 


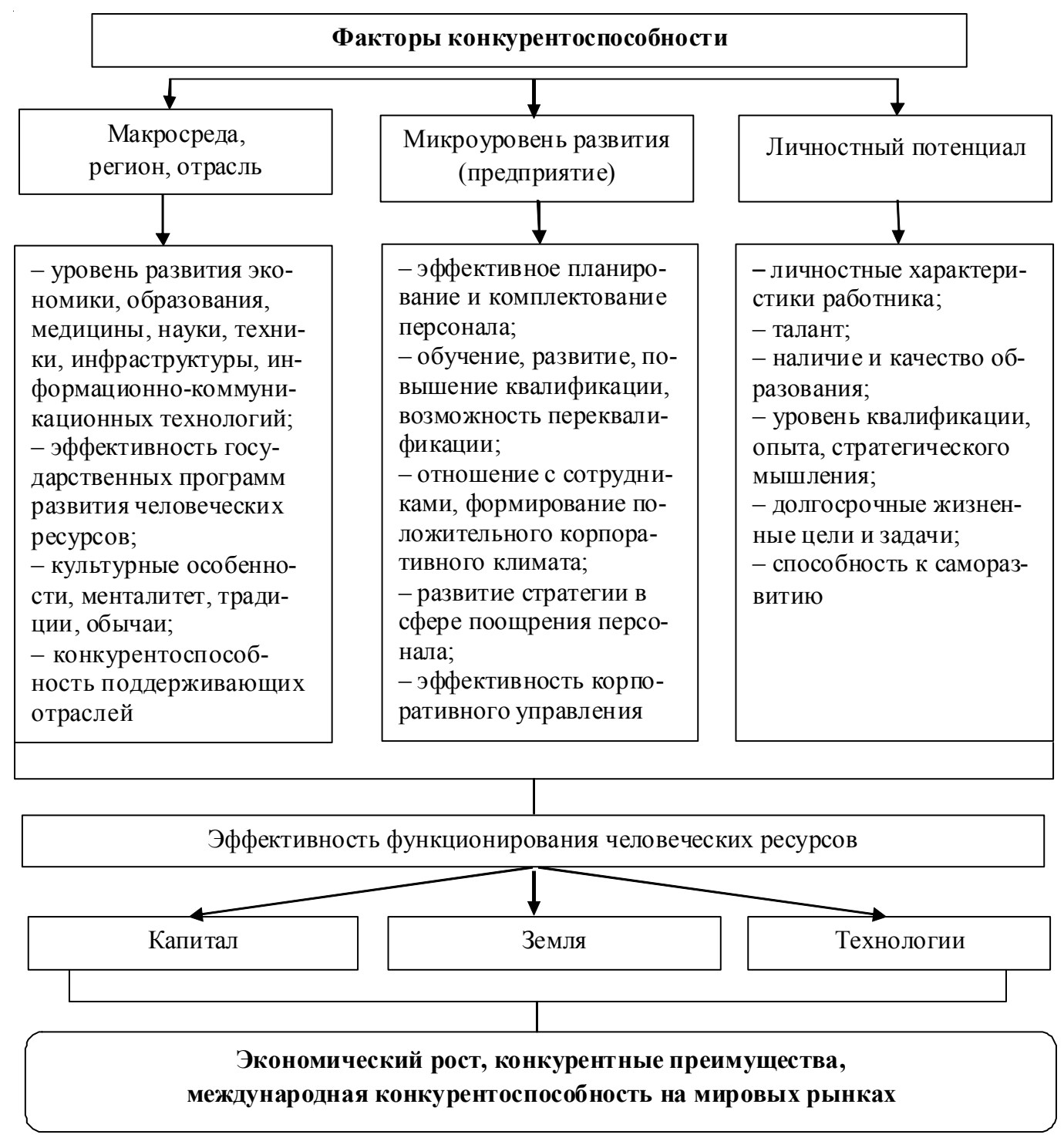

Рисунок. Факторы повышения конкурентоспособности нациольнальной экономики на основе развития человеческих ресурсов

Примечание. Составлено автором на основе проведенного исследования.

Корпоративное разнообразие является важным элементом работы с персоналом. Это неотъемлемый компонент каждого процесса. В связи с этим в концептуальной схеме он принадлежит всем процессам и равномерно распределяется между ними.

Процессы следует рассматривать не как различные и независимые, а как целостную систему стратегического управления человеческими ресурсами с целью обеспечения международной конкурентоспособности. Предложения по изменению трудовых процессов или организационных систем должны сопровождаться анализом влияния всех процессов. Необходимо проанализировать возмож- ные последствия в таких вопросах, как привлечение, интеграция, сохранение и обучение необходимых кадров, материальное благосостояние сотрудников, возможность управления эффективностью в новых организационных условиях. Нельзя внедрять что-то в рамках одной из этих сфер без учета последствий для других.

Нижние уровни предложенной концептуальной схемы демонстрируют, что каждому из процессов присущи стратегические и тактические компоненты.

Так, например, система поощрения. Многие компании выделяют на программы дополнительных помощи и льгот миллионы и даже 
миллиарды долларов. О стратегическом значении этих программ свидетельствуют уже сами масштабы затрат, но важнее проанализировать, какое мотивационное влияние это оказывает на людей. Структура подобных программ свидетельствует о стратегических расчетах руководства в отношении сотрудников и их корпоративной лояльности [Дятлов, 2015, с. 128].

Приведенная схема может помочь специалистам отдела человеческих ресурсов любой корпорации понять связь между работой с персоналом и деловой стратегией. Она может быть основой для консультаций между отделом человеческих ресурсов и менеджментом на предмет различных потребностей и функций. Без этого невозможно провести преобразование и реформирование.

Планирование кадрового состава - самая сложная и самая важная задача в современной работе с человеческими ресурсами.

Компаний, где работа по планированию персонала если и проводится, то крайне поверхностно, значительное большинство. Между тем кадровое обеспечение нельзя осуществить, не имея системы, установки нужных талантов и привлечения их в организацию. Если талант - действительно движущая сила создания любой ценности, то выявление и привлечение необходимых талантов является тем пунктом, с которого начинается весь процесс работы с человеческими ресурсами.

К сожалению, даже в тех компаниях, где план комплектования есть, он во многих случаях привязан к бюджету или просто является его разделом. Первый недостаток данной практики заключается в ошибочной предпосылке, демонстрирующей тот факт, что бюджет адекватно отражает стратегию. Однако это бывает довольно редко. Второй недостаток - восприятие человеческих ресурсов исключительно как статьи расходов, без каких-либо попыток акцентировать внимание на ценности человеческого таланта и выделить его в качестве необходимого стратегического ресурса.

План комплектования должен быть органически связан со стратегией организации и отражать ее кадровые потребности в системе повышения международной конкурентоспособности.
План комплектования человеческих ресурсов - составная часть бизнес-плана. В частности, этот план:

1) четко определяет, сколько работников и какой квалификации необходимо для успешного развития бизнеса;

2) отражает общие задачи бизнес-стратегии и работы с персоналом;

3) включает в себя программу перехода от существующего кадрового состава к предстоящему;

4) является компонентом общего бизнесплана.

План должен быть комплексным. Он решает следующие задачи: условий:

1. Прогнозирование изменений внешних

- тенденции развития отрасли;

- демографические процессы;

- внешние факторы, влияющие на спрос и предложение в сфере трудовых ресурсов.

2. Анализ внутренней ситуации:

- ключевые способности;

- главные роли;

- все изменения в части квалификации, необходимые бизнесу.

3. Прогнозирование будущего кадрового состава:

- по квалификации;

- по должностям;

- по численности;

- по времени.

4. Разработка программы перехода (как именно переходить от существующего состава к будущему).

Фактически это исследование, дающее стратегический прогноз.

Принципы планирования, позволяющие наиболее эффективно прогнозировать потребности в персонале и привлекать нужных людей, представлены следующим образом:

Часть 1. Стратегия бизнеса и ключевые способности. Это самый сложный этап всего процесса. Он требует от руководства наиболее четкой формулировки стратегической позиции, ориентированной на удовлетворение запросов клиентов.

Если нет четкой стратегии, план комплектования лишается смысла. Между тем адекватный кадровый состав - один из важнейших элементов верной стратегии. Если нет 
людей с нужными способностями и опытом, невозможно осуществить стратегические цели и удовлетворить клиентов.

Часть 2. Факторы, влияющие на персонал. Когда бизнес-стратегия определена и служит основанием для плана комплектования, отдел по работе с человеческими ресурсами и руководство намечают факторы, влияющие на кадровую политику. Это те выводы из стратегии, которые требуют изменений в штатном составе. Естественно, выявление таких императивов - задача непростая.

Факторы, влияющие на персонал, - это мотивы, которые диктуют значительное изменение численного и/или квалификационного состава. Они могут быть, например, такими:

- технологические новации, которые существенно влияют на рабочий процесс и, соответственно, требуют изменить численность и квалификацию рабочих;

- ограниченность рынка рабочей силы. Если для некоторых сфер бизнеса прогнозируется нехватка кадров, следует тщательно продумать, как приобрести или сохранить нужных людей;

- цели по повышению индивидуальной производительности. Если поставлена задача повысить производительность, штат, как правило, меняется (сокращается). Также подобные задачи приводят к трансформации производственных процессов, в результате чего возникает потребность в кадрах иной квалификации или в изменении состава специальностей;

- структура рабочих процессов или организации. Значительные реформы вряд ли будут успешными без тщательного планирования нужного кадрового состава по специальностям и численности.

Часть 3. План комплектования. Планирование следует вести как «сверху вниз», так и «снизу вверх». Что касается самого высокого уровня, то еще до определения стратегии следует выявить основные тенденции на рынке труда путем анализа бизнес-среды. Основное планирование начинается после определения стратегии и необходимых для ее реализации способностей. Итогом этой стадии является общий организационно-кадровый план. В него входят основные данные по подразделениям. Руководствуясь этим планом, отделы и подразделения разрабатывают собственные планы согласно определенным кадровым потребностям.

Формат и уровень детализации могут быть различными. Формат должен соответствовать специфическим задачам конкретной организации. При этом в любом случае план составляется так, чтобы процесс комплектования был постоянно ориентирован на стратегические потребности компании. План служит эффективным инструментом, что позволяет отслеживать адекватность имеющейся рабочей силы стратегическим задачам.

Когда факторы, влияющие на кадровую политику, представлены, руководству следует тщательно проанализировать, какие требования предъявляют данные задачи к сотрудникам.

При этом, если исходить из того, что должностное расписание в достаточной степени отражает специфику умений, знаний и личных качеств, и план в конечном счете строится по структуре должностей и специальностей. Из него должно быть ясно, сколько людей и на каких должностях необходимо компании, когда намечаются сокращения и какой график изменений по периодам.

Часть 4. Размещение по рабочим местам и развитие персонала. Наем со стороны. Общий план по персоналу определяет области нехватки и избытка кадров. Для ликвидации недостатка нужна программа найма. Она устанавливает будущие потребности и способы их удовлетворения. Искать кадры можно внутри компании или вне ее. Чем нужнее специалист в стратегическом отношении, тем больше внимания и сил следует уделить его поиску.

Часть 5. План перемещения рабочей силы. Составление плана - один из наиболее важных и сложных этапов работы с персоналом. Именно в этот период выявляются и определяются личные и корпоративные ценности. Принятые решения нередко порождают диспропорцию между потребностью и предложением в сфере кадрового обеспечения. Они имеют финансовые последствия и так или иначе сказываются на отношениях с персоналом.

Если компания приходит к выводу, что она имеет рабочих с квалификацией или спе- 
циальностью, которая больше не нужна, необходимо рассмотреть максимум возможных альтернатив перемещения.

Если компания решит тем или иным образом трудоустроить всех работников, план комплектования должен быть непосредственно ориентирован на реальные потребности бизнеса.

Управление эффективностью - еще одна сфера стратегической работы с персоналом, которая находится на ранней стадии развития. Ее основа - в традиционной системе вознаграждения. Однако ее будущее выходит далеко за пределы теории и практики вознаграждения и связано с эффективностью организации в целом, отдельных ее подразделений и сотрудников в частности.

Сегодня в большинстве компаний ответственные за вознаграждение сотрудники занимаются исключительно разработкой нормативов оплаты труда согласно индивидуальному рыночному уровню. Главные их задачи таковы:

- сбор надежных рыночных данных, показывающих, сколько платят представителям той или иной специальности. Это фундамент традиционной системы вознаграждения и базовый критерий, позволяющий обосновать необходимость той или иной структуры оплаты;

- контроль за фондом зарплаты: руководство должно быть уверено, что бюджетные задачи выдерживаются;

- разработка должностного расписания. Достаточно часто применяются сложные системы оценки в баллах, на первый взгляд, довольно разумные. К сожалению, они нередко исходят из неверных предпосылок относительно того, какую оплату труда предполагает данная должность. Например, в случаях, когда управляющие крупными организациями, действительно заслужили высоких должностей и окладов, которые прописаны системой. При подобном подходе оплачивается объем должностных обязанностей, а не достижение стратегических целей и удовлетворение потребностей клиентов.

Многие группы по вознаграждениям ограничиваются именно такой административной практикой. При этом есть компании, где эта работа приобрела более стратегический характер и направлена на то, чтобы увязать интересы сотрудников с задачами бизнеса в целом, когда учитываются показатели групп и подразделений, а также эффективность управления и производительность на уровне организации.

Эффективность каждого - основа эффективности организации. При этом рост сложности, масштабности и вариантности показателей общей эффективности компании требует новых средств и подходов [Adams, 2007, p. 77].

Управление эффективностью должно стимулировать деятельность всей организации, а не только отдельно взятых сотрудников или групп. Вознаграждение - важный фактор индивидуальной эффективности, но при этом лишь один из немногих, который влияет на результаты всей компании.

Важность управления эффективностью в масштабе всей организации состоит в том, что оно:

- связывает индивидуальные цели с общими;

- связывает индивидуальную эффективность с общекорпоративной;

- обеспечивает необходимую корректировку показателей и целей;

- обеспечивает важнейшие ориентиры для планов по повышению индивидуальной квалификации.

При разработке стратегии развития также следует учитывать, что в условиях кризисных ситуаций при работе с персоналом могут возникать определенные негативные последствия:

- неверие в устойчивость организации в части персонала, что, в свою очередь, может вызвать потерю кадрового потенциала;

- проблема сопротивления персонала изменениям и реорганизации, необходимым для разрешения кризисной ситуации;

- инертность персонала, нежелающего изменять существующее положение;

- ухудшение социально-психологического климата в коллективе.

На основе проведенного исследования можно выделить основные характеристики человеческих ресурсов, которые определяют конкурентоспособность как отдельно взятой компании, так и национальной экономики в целом: численность, образование, квалификация, мобильность, стоимость, личностные и корпоративные конкурентные преимущества, 
продуктивность разработок, возможность и уровень освоения инноваций, эффективность управления работниками, система стимулирования персонала.

\section{Заключение}

Эффективное управление в условиях кризисной ситуации зависит от успешности преодоления информационных, психологических барьеров власти, возникновение которых обусловлено отсутствием в большинстве организаций практического опыта антикризисного управления.

Осознание руководителями необходимости пересмотра концепции и методов управления человеческими ресурсами - это процесс долговременный. Понимание объективности современных тенденций необходимо положить в основу разработки соответствующих предупредительных антикризисных мер, а для этого особое внимание следует уделить формированию антикризисного мышления.

Комплексный подход к формированию механизма управления человеческими ресурсами в условиях кризисных ситуаций направлен на разработку мер по выходу из кризиса. Он будет способствовать повышению эффективности работы с человеческими ресурсами, а значит, повышению конкурентоспособности не только на национальном, но и на международном уровне.

\section{СПИСОК ЛИТЕРАТУРЫ}

Айдинова, А. Т. Пуги повышения конкурентоспособности предприятий / А. Т. Айдинова, Е. С. Головко// Молодой ученый. -2015 . - № $12 .-371 \mathrm{c}$.

Алавердов, А. Р. Управление человеческими ресурсами организации : учебник / А. Р. Алавердов. - М. : МФПУ Синергия, 2015. - 656 с.

Аранжин, В. В. Ключевые факторы повышения конкурентоспособности современных организаций (по материалам российских научных публикаций) / В. В. Аранжин // Современные научные исследования и инновации. - 2017. № 2. - Электрон. текстовые дан. - Режим доступа: http://web.snauka.ru/issues/2017/02/ 78086 (дата обращения: 07.05.2020). - Загл. с экрана.

Базык, Е. Управление человеческими ресурсами как фактор повышения конкурентоспособности организации / Е. Базык // Экономика и предпринимательство. - 2015. - № 1. - С. 1-8.

Баканова, Е. Человеческие ресурсы: проблемы инновационного развития и использования : сб. науч. тр. / Е. Баканова. - Вып. 3. - Кемерово : Кемер. гос. ун-т, 2014. - 262 с.

Балтабек, Д. Ж. Влияние эффективности управления персоналом на конкурентоспособность фирмы / Д. Ж. Балтабек // Международный научно-исследовательский журнал. - 2016. № 10 (52). - C. 6-7.

Биганова, Г. Г. Формирование и развитие HR-службы как фактор конкурентоспособности организации / Г. Г. Биганова, А. Д. Межевов // УПравление. -2017 . - № 3 (17). - С. 21-25.

Богатырева, М. Р. Планирование карьеры посредством развития трудового потенциала работника / М. Р. Богатырева, А. Л. Шкильдина // Гуманитарные научные исследования. - 2014. - № 3.Электрон. текстовые дан. - Режим доступа: http://human.snauka.ru/2014/03/6004 (дата обращения: 15.05.2020).- Загл. с экрана.

Веснин, В. Р. Практический менеджмент персонала : пособие по кадровой работе / В. Р. Веснин. М. : Юрист, 2003. -495 c.

Воронина, В. Россия: экономический рост / В. Воронина - М. : Финансовый контроль, 2016. $75 \mathrm{c}$.

Дейнека, А. В. Управление человеческими ресурсами: учебник для бакалавров / А. В. Дейнека, В. А. Беспалько. - М. : Дашков и К, 2015. $-392 \mathrm{c}$.

Дятлов, С. А. Основы теории человеческого капитала / С. А. Дятлова. - СПб. : Изд-во Санкт-Петербург. ун-та экономики и финансов, 2015. -160 c.

Егоршин, А. П. Основы менеджмента: учебник / А. П. Егоршин. - 3-е изд., доп. и перераб. М. : НИЦ ИНФРА-М, 2015. - 350 c.

Кови, С. Лидерство, основанное на принципах : пер. с англ. / С. Кови. - М. : Альпина Бизнес Букс, 2015. $-200 \mathrm{c}$.

Adams, C. The 'Standardization' of Sustainability Reporting, Cited in Sustainability Accounting and Accountability / C. Adams, V. Narayanan; ed. by B. O'Dwyer, J. Bebbington, J. Unerman. Routledge : Oxen, 2007. - P. 70-85.

Moskowitz, M. Choosing Socially Responsible Stocks / M. Moskowitz // Business and Society Review. 1972. - № 1. - P. 71-75.

Moskowitz, M. Profiles in Corporate Responsibility / M. Moskowitz // Business and Society Review. - 1975. - № 13. - P. 29-42.

Potter, W. J. Rethink Invalidity and Reliability in Content Analysis / W. J. Potter, D. Levine Donnerstein // J. Appl. Commun. Res. - 1999. Vol. 27 (3). - P. 258-284. 


\section{REFERENCES}

Ajdinova A.T., Golovko E.S. Puti povysheniya konkurentosposobnosti predpriyatiy [Ways of Enterprise Competitiveness]. Molodoy uchenyy [Young Scientist], 2015, no. 12.371 p.

Alaverdov A.R. Upravlenie chelovecheskimi resursami organizatsii [Human Resource Management of the Organization]. Moscow, MFPU Sinergiya Publ., 2015.656 p.

Aranzhin V.V. Klyuchevye faktory povysheniya konkurentosposobnosti sovremennykh organizatsiy (po materialam rossiyskikh nauchnykh publikatsiy) [Key Factors of Increasing the Competitiveness of Modern Organizations (Based on Materials from Russian Scientific Publications)]. Sovremennye nauchnye issledovaniya i innovatsii [Modern Scientific Researches and Innovations], 2017, no. 2. URL: http://web.snauka.ru/issues/2017/ 02/78086 (accessed 7 May 2020).

Bazyk E. Upravlenie chelovecheskimi resursami kak faktor povysheniya konkurentosposobnosti organizatsii [Human Resource Management as a Factor in Increasing the Competitiveness of an Organization]. Ekonomika i predprinimatelstvo [Journal ofEconomy and Entrepreneurship], 2015, no. 1, pp.1-8.

Bakanova E. Chelovecheskie resursy: problemy innovatsionnogo razvitiya $i$ ispolzovaniya: $s b$. nauch. tr. [Human Resources: Problems of Innovative Development and Use: A Collection of Scientific Papers]. Iss. 3. Kemerovo, Kemerovskiy gosudarstvennyy universitet, 2014. $262 \mathrm{p}$.

Baltabek D.Zh. Vliyanie effektivnosti upravleniya personalom na konkurentosposobnost firmy [The Influence of the Effectiveness of Personnel Management on the Competitiveness of the Company]. Mezhdunarodnyy nauchnoissledovatelskiy zhurnal [International Research Journal], 2016, no. 10 (52), pp. 6-7.

Biganova G.G., Mezhevov A.D. Formirovanie i razvitie HR-sluzhby kak faktor konkurentosposobnosti organizatsii [Formation and Development of the HR Service as a Factor in the Competitiveness of the Organization]. Upravlenie, 2017, no. 3(17), pp. 21-25.

Bogatyreva M.R., Shkildina A.L. Planirovanie karyery posredstvom razvitiya trudovogo potentsiala rabotnika [Career Planning Through the Development of an Employees Labor Potential]. Gumanitarnye nauchnye issledovaniya, 2014, no. 3. URL: http://human.snauka.ru/2014/03/ 6004 (accessed 15 May 2020).

Vesnin V.R. Prakticheskiy menedzhment personala: posobie po kadrovoy rabote [Practical Personnel Management: A Guide to Human Resources]. Moscow, Yurist Publ., 2003. 495 p.

Voronina V. Rossiya: ekonomicheskiy rost [Russia: Economic Growth]. Moscow, Finansovyy kontrol Publ., 2016. 75 p.

Deineka A.V., Bespalko V.A. Upravlenie chelovecheskimi resursami: uchebnik dlya bakalavrov [Human Resource Management. Textbook for Bachelors]. Moscow, Dashkov i K Publ., 2015. 392 p.

Dyatlov S.A. Osnovy teorii chelovecheskogo kapitala [Fundamentals of Human Capital Theory]. Saint Petersburg, Izd-vo Sankt-Peterburgskogo universiteta ekonomiki i finansov, 2015. $160 \mathrm{p}$.

Egorshin A.P. Osnovy menedzhmenta: uchebnik [Fundamentals of Management: Textbook]. Moscow, NITs INFRA-M, 2015.350 p.

Kovi S. Liderstvo, osnovannoe na printsipakh: per. s angl. [Principled Leadership. Translated from English]. Moscow, Alpina Biznes Buks Publ., $2015.200 \mathrm{p}$.

Adams C., Narayanan V. The Standardization of Sustainability Reporting, Cited in Sustainability Accounting and Accountability. Routledge, Oxen, pp. 70-85.

Moskowitz M. Choosing Socially Pesponsible Stocks. Business and Society Review, 1972, no. 1, pp. 71-75.

Moskowitz M. Profiles in Corporate Responsibility. Business and Society Review, 1975, no. 13, pp. 29-42.

Potter W.J., Levine Donnerstein D. Rethink Invalidity and Reliability in Content Analysis. J. Appl. Commun. Res., 1999, vol. 27 (3), pp. 258-284. 


\section{УПРАВЛЕНИЕ ЭКОНОМИЧЕСКИМ РАЗВИТИЕМ}

\section{Information About the Author}

Elena S. Shilets, Doctor of Sciences (Economics), Professor, Department of International Economics, Donetsk National University, Universitetskaya St, 24, 283001 Donetsk, Donetsk People's Republic, shilec1@mail.ru, https://orcid.org/0000-0002-7454-3353

\section{Информация об авторе}

Елена Станиславовна Шилец, доктор экономических наук, профессор кафедры «Международная экономика», Донецкий национальный университет, ул. Университетская, 24, 283001 г. Донецк, Донецкая Народная Республика, shilec1@mail.ru, https://orcid.org/0000-0002-7454-3353 